\title{
A review of the customer lifetime value as a customer profitability measure in the context of customer relationship management
}

\author{
Raphael Damm, Carlos Rodríguez Monroy \\ Universidad Politécnica de Madrid (Spain) \\ raphael.damm@alumnos.upm.es, crmonroy@etsii.upm.es
}

Received December, 2010

Accepted J une, 2011

\section{Abstract}

Purpose: A number of customer metrics allow estimating customer profitability with methods such as the Customer Lifetime Value (CLV). However, investments in customer relationships carry the potential risk to destroy value and reduce profitability when based on incorrect estimates of customer profitability. Therefore, estimating future customer value correctly is essential to allocate marketing expenditures in the most effective way. In this article recent literature about the CLV is reviewed in order to assess its ability as a customer profitability measure.

Besides the financial perspective of the CLV, non-financial perspectives such as customer advocacy, (customer or open) innovation and learning have been identified to have an impact on customer profitability. How to properly estimate a customer's value taking all relevant value creating factors, financial as well as non-financial, into account is the underlying research question.

Design/ methodology/ approach: This research is based on the review of a number of theoretical and empirical articles published between 1990 and 2010. The aggregation of measures, key-drivers and risks of each keyperspective of the customer relationship contributes to the development of a more systematic understanding of the value creation process and provides answers to the research question. Indirect effects of the CLV as a source of 
value have received increasing attention in previous research but are not sufficiently accounted for by mainstream methods for valuing customers (Ryals, 2008). Therefore, the attempt to structure available knowledge on indirect effects of the CLV in its contextual setting is made.

Findings: This research is concluded providing evidence that onedimensional calculations of the CLV deliver an incomplete picture of the customer relationship and estimate customer profitability incorrectly. This supports the idea of a multidimensional CLV approach that accounts for interrelated key-perspectives and results in superior resource allocation.

Originality/value: Seeing customers in a comprehensive way helps to better understand their needs and potential contributions, so that long-term overall profitability can be advanced through the consideration of indirect effects. Indirect effects are usually not reflected in common accounting methods but might result in benefits for the firm. In this research, evidence is provided for the importance of indirect effects offered by customers. This makes the consideration of all relevant dimensions in the value creation process fundamental in order to allocate marketing resources in the most effective way.

Keywords: customer lifetime value, customer profitability, non-financial values, customer relationship management

Jel Codes: M31

\section{I ntroduction}

The ever-present need to justify investments in marketing activities, calls for marketing measures that can be linked to future customer value and firm performance (Peterson et al., 2009). The CLV approach captures customer metrics in order to quantify the potential monetary value of customers over their lifetime. This allows better estimating customers' financial values, focusing on profitability, grouping customers and analyzing the returns on investments made into customers. The purpose of the CLV is to increases marketing's accountability within the firm, help managers and retailers to identify the drivers of future customer and firm value and build linkages between marketing strategy and financial outcomes 
(Peterson et al., 2009). However, applying the CLV also leads to a number of questions.

1. Does the valuation take all relevant value creating factors into account so that the CLV is properly estimated?

2. Does the CLV properly account for risks inherent in customer relationships such as customer defection or negative customer advocacy?

3. Do forecasting difficulties limit the practical use and acceptance of the CLV?

The CLV takes direct customer spending into account but does not incorporate indirect revenues from additional sales through Word of Mouth (WOM) or the likes. In addition, neither savings that result from customer triggered process optimizations are subject of the CLV, nor are reductions of uncertainties resulting from reliable customer relationships reflected by the CLV. That raises the question if customer profitability will be estimated correctly when neither customer advocacy, the innovation potential nor the learning potential are accounted for. Moreover, will marketing expenses be utilized in the most adequate, that is, profitable way if long-term overall customer profitability is estimated incorrectly not accounting for important value creating potentials?

Relationships might be seen as emotional selling propositions due to the fact that satisfied customers return to trusted companies (Urban, 2005). The Customer Relationship Management (CRM) aims at establishing long-term relationships with customers in order to gain insights into what matters most to customers. Insights into specific customer needs enable companies to better target and satisfy them and provide knowledge for potential product developments. Measuring and comparing the costs to acquire and to maintain customers are prerequisites in order to be able to decide focusing on customer retention or on customer acquisition. Although it is commonly accepted that it is important to measure what is to be managed there are important aspects that are unobservable but nevertheless need to be managed.

As the CLV is estimated over a number of transactions, that are likely to occur throughout the customer lifetime, it cannot be seen in an isolated way but rather in the long-term relationship context that CRM suggests. The CLV can therefore be seen as a tool that allows the calculation of potential customer value only if a (longterm) relationship exists. The contextual settings, such as long-term relationship, customer satisfaction, customer learning and others that are suggested by the CRM approach are crucial, as CLV estimates will only be calculated correctly if contextual 
settings support the compliance of customer metrics. Expected lifetime, retention rate and others are CLV determining elements that are strongly influenced by the contextual settings. Hence, an overview of the CRM approach is necessary to understand the contextual settings that are required for the calculation of the CLV.

\section{A brief review of the customer relationship management concept}

The CRM approach reflects the shift from functional traditional marketing, focused on products and customer acquisition, towards comprehensive marketing that puts the relationship with the customer first. The essence of CRM is to change organizations from a products-centric to customer-centric philosophy (Kim et al., 2003). Developments in technology have enabled companies to see customer relationships more holistically provoking this change from transactional to relationship marketing (Alt et al., 2005). Although technologies play a crucial role in CRM enabling the aggregation of customer data and the recognition of patterns, they are not subject of this research and will not be discussed here.

The central idea behind engaging customers in long-term relationships is to increase company and customer value by systematical management of existing customers. Kim et al. (2003) summarize the following potential benefits of CRM:

- Increased customer retention and loyalty

- Higher customer profitability

- Creation value for the customer

- Customization of products and services

- Lower process, higher quality products and services

The tangible effects of companies' commitment to retaining customers were first published by Dawkins and Reichheld (1990) who claim that higher retention rate leads to higher net present value of customers (Ahmad \& Buttle, 2002). The selection and acquisition of customers based on the purely financial CLV become critical to the long-term customer profitability. The CLV as the measure for customer profitability possesses a fundamental role as it serves within the customer analysis as a deciding feature. The correctness of the CLV in terms of long-term overall customer profitability consequently turns out to be essential for the most efficient employment of marketing expenditures. 
The review of literature on the CRM approach has revealed the existence of varying definitions (Reinartz et al., 2004; Payne \& Frow, 2005; Richards \& Jones, 2008) and an imperfect conceptualization of the CRM concept (Magro \& Goy, 2008). The aim of a conceptualization is to provide a general definition and categories, so that areas can be classified and grouped accordingly. A formalized ontology building process is suggested by Pinto and Martins (2004). They state specification, conceptualization, formalization, implementation and maintenance as the usually accepted stages. As this research focuses on the CLV as a customer profitability measure no attempts to develop a CRM ontology are made. Though, the aggregation of specifications that have been mentioned throughout academic literature might contribute to the development of a CRM ontology. The following table shows different approaches to define dominant perspectives on CRM.

\begin{tabular}{|c|c|}
\hline Authors & Perspectives on CRM \\
\hline Reinartz el al. (2004) & $\begin{array}{c}\text { Functional } \\
\text { Customer-facing } \\
\text { Companywide }\end{array}$ \\
\hline Teo et al. (2006) & $\begin{array}{c}\text { Technology } \\
\text { Customer } \\
\text { Business }\end{array}$ \\
\hline Zablah et al. (2004) & $\begin{array}{c}\text { Process } \\
\text { Strategy } \\
\text { Philosophy } \\
\text { Richards et al. (2008) }\end{array}$ \\
& Technolity \\
\hline
\end{tabular}

Table 1. Different perspectives on CRM

Although the CRM approach is not fully conceptualized several crucial aspects that are usually mentioned when referring to CRM may be named. CRM is not a technology but it is tied to technologies as it has developed with information technology. Analyzing customer data on a large scale is only possible due to technology. Therefore, technology might be seen as one of the fundamental perspectives of CRM (Alt et al., 2005). The process based view of CRM seems to be the most accepted view of CRM. It reflects the fact that relationships develop over time and must progress to continue. Further, the strategy based view of CRM assumes that customers are not equally profitable and resources have to be allocated accordingly to their expected lifetime value in order to maximize profitability. This is an important insight that needs to receive closer attention especially on the issue of how to determine a customer's potential value including non-financial values. The importance to distinguish different stages in a customer's relationship is highlighted by Reinartz et al. (2004) for the following four reasons: 
1. The essence of the marketing concept is building and managing ongoing customer relationships.

2. Relationships evolve with distinct phases.

3. Firms interact with customers and manage relationships at each stage.

4. The distribution of relationship value to the firm is not homogenous.

There are three primary dimensions, which are relationship initiation, maintenance and termination, which are further divided into sub dimensions. The performance of CRM activities critically depends on situational factors that influence the type of relationship. The recognition of the fact that relationships evolve with distinct phases leads to the insight that customers have to be treated differently in accordance with the stage in their lifecycle. At the beginning of a relationship customers are more valuable due to the future potentials that they offer (Ryals, 2002). The underlying question in a non-contractual setting will always be whether customers are still with the firm or whether they have defected to competitors or have abandoned the technology. The above mentioned aspects are important issues to be taken into account when applying the CLV. An adequate structure of the CRM concept in order to organize them is needed though. A comprehensive framework that differentiates between broad perspectives and then narrows down dividing each one into further categories would help to understand more accurately what is meant, in what context and at what level when referring to CRM.

\section{A literature review of the customer lifetime value concept}

A strong concentration on the financial aspects of the CLV has been determined in the reviewed articles. However, other aspects such as customer advocacy, customer innovation or customer learning have been recognized, even though, by far not with the same attention. The reasons for less attention to other than financial aspects are diverse. First, factors that are commonly considered being important are missing, second, practical mainstream methods that would allow assessing a concrete financial value to non-financial aspects do not exist, and third, the potential of non-financial aspects to impact indirectly on financial factors is not recognized adequately. That is consistent with Gupta and Zeithaml (2006) citing Ittner and Larcker (1996) who state that customer metrics are perceived less important than financial measures because they are not clearly defined. 

1.) $C L V=\sum_{t=1}^{n} \frac{R_{t}-C_{t}}{(1+d)^{t-0,5}}$
2.) $C L V=\sum_{t=0}^{n} \frac{m_{t} * r_{t}}{(1+d)^{t}}$
3.) $\operatorname{CLV}=\frac{m * r}{(1+d-r)}$

$\mathrm{R}_{\mathrm{t}}$ : Customer's benefits in period $\mathrm{t}$

$C_{t}$ : Total cost of generating benefits $\left(R_{t}\right)$ in period $t$

$\mathrm{n}$ : Total number of anticipated periods

d: Discount rate

$\mathrm{m}_{\mathrm{t}}$ : Gross margin in period $\mathrm{t}$

$r_{t}$ : Retention rate in period $t$

Figure 1. Selected formulas for calculating the CLV; 1.) Jain \& Singh, 2002 2.) Berger \& Nasr, 1998 3.) Zhang et al., 2010

The original CLV concept is based on the idea to justify marketing expenditures by applying the net present value (NPV) method to investments made in customer relationships. More recently, acknowledgments in academic literature of the importance of non-financial effects have led to further research investigating the accountability of non-financial effects. This suggests a multidimensional customer profitability measurement rather than one single silver metric. Yet, the challenge is to overcome measurement difficulties of non-financial effects and to determine their impact in a quantifiable way. The CLV states the present value of a customer relationship over the lifetime with a company. Customer equity refers to the total lifetime value of a company's customer base (Hogan et al., 2004). Kumar and Rajan (2009) define the CLV as: "The sum of cumulated cash flows-discounted using the weighted average cost of capital (WACC)-of a customer over his or her entire lifetime with the company."

The measures that determine the monetary value of the CLV are generally the revenues from a customer and the costs of attracting, selling, and servicing that customer. A number of assumptions may be made in order to illustrate the CLV concept and its calculation in different scenarios. Revenues may be generated annually, more frequently or less frequently as well as the amount of revenues might be constant or variable and discrete or continuous over time. The same is valid for the rest of the variables determining the CLV.

It has been suggested that constant margins and retention rates be used in order to simplify calculations and in order to overcome the need for intensive data. Zhang et al. (2010) state that the CLV formula can be simplified to a great extent when margins and retention rates are assumed to be constant and lifetime estimated to be infinite. In the case of assuming infinite lifetime the retention rate automatically accounts for reduced probability to continue the relationship. This reduces the complexity of the CLV to a great extent and adequately reflects reality. 
An extensive discussion of different mathematical models for computing the CLV in selected scenarios has been given, for example, by Berger and Nasr (1998) and Jain and Singh (2002) and will therefore not be repeated here. However, the quantification and the weighting of indirect non-financial measures are important pending and also difficult task. Not taking account of indirect non-financial effects means estimating the CLV incorrectly and consequently failing to address customers with the adequate individual marketing effort (Lee et al., 2006).

"If marketing expenditures are an investment, and the creations of marketing are assets, then it is of utmost concern that these assets be valued by metrics in use. Likewise, should the metrics be misleading, this can lead to a plethora of problems, including rash investments based on inaccurate heuristics; or the canceling of certain programs that are deemed unsuccessful by virtue of the misleading measure" (Seggie et al., 2007: page 835).

CRM is the intent to understand each customer and then deliver a consistent massage or service to that customer (Urban, 2005). The CLV is a tool that helps estimating the financial potential of customers, but to put together the big picture more information is needed. By helping customers find the appropriate product or service, companies can build up trust and learn what customers really want. For example, neglecting customers' attitudes and aggressively cross-selling to them when not requested might result in customer defection. In contrast, having gained customers' trust through honest behavior might provide enduring advantage as competitors struggle to convince customers to take the risk and switch to a different company (Urban, 2005). The foundation of those findings is that price is not the only criterion that wins the battle. Depending on the product category and the importance that a product or service has got to customers, the emotional attachment might prove just as beneficial as quality, technology or price leadership.

Approaches towards defining indirect customer value and gauging its monetary value have been made by a number of researchers. Ryals (2008) explored the process of valuing indirect benefits from customer relationships analyzing advocacy, learning and innovation benefits. Von Hippel and Katz (2002) explored the implications of toolkits for user innovation. Bermejo and Rodríguez-Monroy (2010) analyzed the factors of an equation presented by Stahl et al. (2003) to measure the customer value in a B2B environment taking into account the base, growth, networking and learning potential. Hogan et al. (2003) focused on indirect social effects such as WOM and Kumar et al. (2010) proposed the customer engagement 
value (CEV) including the CLV, the customer referral value, the customer influencer value and the customer knowledge value.

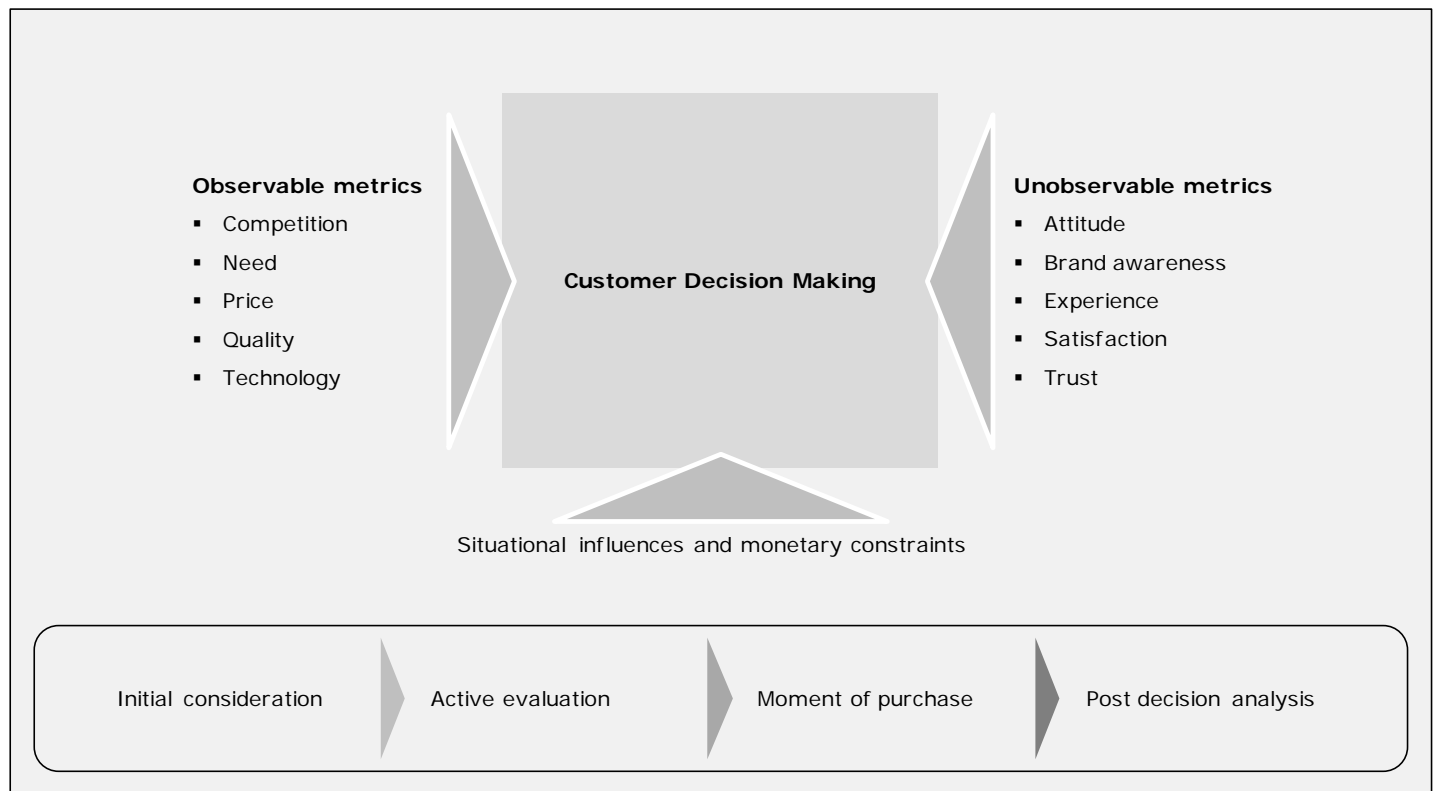

Figure 2. Factors influencing the customer decision making

In particular, advocacy with a focus on WOM has received considerable attention in academic literature. The learning and innovation potentials that customers offer, have received less attention from researchers in the context of the CLV. Customer led innovations offer multiple benefits such as reduced time-to-market, reduced cost-to-market or increased fit-to-market (Piller, 2006). Those benefits do have an impact on financial measures, even though they might impact in an indirect way. The same is valid for the learning potential. Knowledge about customers is actually the basis of the CRM approach and it is essential for correct customer segmentation and customer treatment consequently reducing the risk to do business with loss making customers. Better resource allocation and increased market intelligence also result from customer learning (lyengar et al., 2007). The quantification of nonfinancial effects is needed in order to make them comparable to financial measures. This would allow deciding if financially unprofitable customers might offer advocacy, learning or innovation potentials that would offset their unprofitability and make them indirectly profitable. Or, if already profitable customers, in financial terms, might prove even more profitable through the utilization of their advocacy, learning or innovation potential.

\section{The effects of the customer advocacy potential on the CLV}

Generally, referrals lead to lower acquisition costs and in addition existing loyal customers refer new customers that are more loyal themselves (Reichheld, 1996 
quoted in Ryals, 2002). Therefore, outsourcing the customer acquisition process will lead to a competitive advantage if conventional marketing efforts would be reduced maintaining the customer acquisition rate or if additional customers would be attracted with the same marketing efforts. Customer advocacy may be defined as any interaction between customers and their environment in a direct or indirect manner.

Bughin et al. (2010) estimate WOM to be the primary factor behind 20 to 50 percent of all purchasing decisions with greatest influence on customers that buy a product for the first time or when products are relatively expensive.

Nevertheless, there is a wide range of other sources besides direct customer-tocustomer communication from which customers can obtain information. An increase in communication between customers, due to the developments in information technology, has amplified and accelerated WOM marketing drawing increasing attention to customer advocacy. Bughin et al. (2010) mention experiential, consequential and intentional as three forms of WOM.

Concerning the quantification of customer advocacy Kumar et al. (2007) developed an approach to calculate what they call the Customer Referral Value (CRV). As for the CLV a number of measures need to be estimated. These include the number of successful referrals, the period $(t)$ of time in which referrals can be related to a marketing activity, the number of customers that would have become customers without any recommendation $\left(n_{2}-n_{1}\right)$, the revenues generated by customer y who otherwise would not buy the product $(A)$, the discount rate $(d)$, the cost of the referral for the attracted customer y $(a)$, the marketing costs needed to retain the referred customer $(M)$, the savings in acquisition cost from customers who would have joined anyways (ACQ2) and those who would not join without the referral (ACQ1).

$$
\mathrm{CRV}_{i}=\sum_{t=1}^{T} \sum_{y=1}^{n 1} \frac{A_{t, y}-a_{t, y}-M_{t, y}+A C Q 1_{t, y}}{(1+d)^{t}}+\sum_{t=1}^{T} \sum_{y=n 1}^{n 2} \frac{A C Q 2_{t, y}}{(1+d)^{t}}
$$

Figure 3. Formula for calculating the Customer Referral Value (Kumar et al., 2007)

However, the CRV can only estimate the value of consequential referrals that have been triggered by marketing campaigns and there is also the issue about double counting as one customer's CLV is potentially similar to the CRV of the customer who made the referral. Voluntary referrals are more challenging to comprehend. 
What make them so powerful are their origin and their impact. To better understand on what the impact of recommendations depend, it has to be determined who recommends what and where or in which context the recommendation is made. Kumar et al. (2007) found in their analysis of a telecommunications firm that the most loyal customers meaning customers with the highest financial CLV were not its strongest advocates. Customers that they call advocates were, despite having a low CLV, almost as valuable as customers with high (financial) CLV taking referrals into account. This demonstrates that indirect values can offset direct low profitability.

Drivers that have been identified in the literature to have an impact on the above mentioned factors include the following. The identity of the person who spreads WOM influences whether the receiver of the recommendation trusts the sender and believes that the sender knows the product or service in question. Bughin et al. (2010) found that across most product categories important product or service features have to be addressed in order to influence customer decisions. It is crucial to understand which product features are considered important as addressing product features with no significance to the customer does not create any attraction and is therefore unnecessary. Lastly, the environment where WOM is spread determines the impact of the referral. Referrals with less reach have a greater impact than those spread through far-reaching networks. The reason might be the correlation between the number of people one trusts and the number of network members one values.

WOM has been shown to be a potential source of additional sales and cost reduction. Marketing activities result more effective through lower acquisition costs and moreover referrals help to reduce post purchase cognitive dissonances through the confirmation of purchase decisions. WOM also makes the decision-making process for new customers simpler and faster which leads to faster market penetration (Stahl et al., 2003).

\section{The effects of the customer innovation potential on the CLV}

In the early stages of the innovation process uncertainties have to be eliminated in order to overcome market and technology risks. Customers that gain specific knowledge from experiencing products or services in broad ranges of contexts might be seen as sources of need and solution information that can help to reduce uncertainties. In the open innovation concept innovations are seen as the result of loosely coordinated and open networks of a number of users and customers (Piller, 2006). The success depends on the ability of companies to establish networks with 
external actors (suppliers, customers, competitors, and external Research and Development $(R \& D)$ institutions) along the innovation process.

Potentially, a reduction in time to market is achieved by reducing cycle time in the trial and error process due to constant feed-back in the early stages of the development process. Access to a greater number of resources presents extended solution finding and cost saving potentials (von Hippel and Katz, 2002) and further, the participation of potential customers seems to increase the fit to market and their willingness to pay (Franke et al., 2010). Other results from innovative activities with external partners might be product or process innovations which could lead to increases in revenues and cost reductions.

The profound understanding of the usage and the application environment of the users are the key-drivers for need information. The broader access to need and solution information provides an extended idea and solution finding potential reducing not only the market and technology risks but also the risk of investments in innovative activities. A key driver for successful customer or user innovation is the supply of an adequate arena that unites different sources and knowledge perspectives in an interactive and directed problem-solving-process (Piller, 2006). Solving the interface problem by the development of appropriate toolkits provides access to sticky information and offers therefore the chance to better define customer needs through a "learning by using" process and the conceptualization of available customer owned information. Information's stickiness can be reduced by converting tacit knowledge into explicit knowledge (von Hippel and Katz, 2002).

\section{The effects of the customer learning potential on the CLV}

The learning potential inherent in customer relationships can be utilized to increase a company's market intelligence and to improve a number of other factors. Knowing how to satisfy customers' needs or what causes customers to engage in long-term relationships enables marketers to reduce expenses up to the critical level maximizing efficiency of scarce marketing resources. Further, through the learning process resources can be allocated in a more adequate way attributing fixed costs of specific products or services more precisely.

Iyengar et al. (2007) investigated consumer learning for service quality and usage in wireless service. They found that consumer learning can result in a win-win situation for both customers and the company due to less minutes spent by the customers and an increase of $35 \%$ of the overall CLV. Learning can boost 
product/service and process improvements and innovations which increase efficiency and quality and reduce uncertainties.

Rather than reducing acquisition costs or increasing the number of customers the learning potential is a source of knowledge. It offers the opportunity to improve the understanding of customers' latent and overt needs or problems, products' true performance, competitors' capabilities and strategies or technological trends.

Knowledge taken from individual customer relationships might reduce relationship costs as process improvements can be applied to whole segments of the customer base. The intimacy of the customer relationship permits to develop, test and refine different types of knowledge, such as market conditions, technologies and business processes or future trends (Stahl et al., 2003). The knowledge acquired through the learning process can be converted into more reliable forecasts and plans to better understand customer needs and improve product and process quality. Further, more reliable forecasts help to decrease cash flow vulnerability and volatility.

Customers' consumption pattern are results of their needs, influenced by the level of uncertainty as well as quantity and quality learning over time. Iyengar et al. (2007) found the level of quality of service encounters to provide a strong signal for the overall service quality in wireless services. Therefore, customers' needs can be positively influenced by satisfying what matters to customers. At the same time wasteful spending on non-critical factors recognized through learning might be reduced or eliminated. More straightforward measures that can show the results of the knowledge creation process through interaction are the time needed for new product development, the level of market penetration related to time and the number of product and process improvements or innovations.

The successful utilization of the learning potential depends mainly on the ability to establish relationships with customers and to motivate them to share their specific knowledge. Further, success is driven by the ability to structure obtained knowledge and make it available. New product developments might result to have less false starts and delays, reduced time to market and increased market acceptance.

\section{Conclusions}

The CRM approach is one promising attempt to team up with the customer and respond to the change in power by creating a comprehensive marketing philosophy. Accountability for marketing activities has put the focus mainly on financial 
measures. This has raised doubts if customer profitability is estimated correctly. As it has been shown in this article research provides strong evidence that supports doubts about the correct estimation of overall customer profitability.

The aim of this article was to discuss the CLV as a profitability measure in the context of CRM. The reviews of the CRM approach and the CLV framework have shown that they are not fully conceptualized and commonly understood. CRM lacks a systematical approach and commonly accepted definition. Nevertheless, a trend towards seeing CRM as a holistic philosophy that helps implement marketing strategies, rather than seeing CRM itself as a strategy, is evolving.

Investments in customer management are subjected to be profitable. This requires measures, so that resource allocations can be compared and justified. Given the diversity of customers it is crucial to evaluate their potential value properly and develop adequate relationship strategies. Taking all relevant dimensions into account and determining success as well as risk factors in the value creation process is fundamental to allocate marketing resources in the most effective way. However, the exact quantification in financial terms of the voluntary customer advocacy, innovation and learning potential remains a pending task.

Increasing competition and maturing markets call for increases in efficiency and productivity in order to reduce costs. Increases in sales not only help to compensate decreasing margins but are also crucial for the degree of capacity utilization. This serves to cover fixed costs. Eliminating unprofitable customers would lead to allocating fixed costs to a smaller number of (profitable) customers, consequently reducing their profitability. Therefore, the comprehensive view of customers helps to better understand their needs and potentials so that long-term overall profitability can be advanced through the consideration of indirect effects by generating more sales through referrals, for example. Adequate customer treatment in accordance with the stage in their lifetime with the company is another cost neutral learning insight that results in more efficient resource allocation.

A fundamental issue that should be attended in future research is the question about what drives the wish to engage in a relationship. Mainly the interest of customers in a product or service and the importance of a product or service (value) have been mentioned to drive willingness to engage in relationships. What exactly are the crucial drivers of relationships? Are they trust, reliability, price or others? This certainly depends on the product category and should be investigated further taking this into account. 
Overall, this research has shown that customers offer more than their financial value and that indirect effects play a crucial role that need to be accounted for. Although it has not been accomplished to develop straightforward measures that would allow putting a concrete financial value on the advocacy, learning and innovation potential, it has been demonstrated what drives the crucial factors that determine the key-perspectives of customer relationships. Measuring the results cannot always be done in financial terms, which makes it hard to convincingly state the importance of other than financial measures. Although they are hard to quantify increased knowledge about processes, product behavior, customer needs and demands as well as longer customer lifetime, increased revenues, cost reductions and increased market intelligence are crucial success factors that provide competitive advantages.

The nature of marketing makes it necessary that a holistic view is applied to investments in marketing activities as those aim to create intangible assets. A purely financial CLV will therefore estimate customer profitability incorrectly. Concluding with the insight that customer profitability cannot be simply explained with customer loyalty, relationship duration or another single silver metric, advocates a multi-dimensional CLV. Therefore, further research is needed to develop other approaches to evaluate long-term overall customer profitability and test them empirically. Further developing a comprehensive understanding of marketing accountability will result in increase in transparency and finally contribute to better resource allocation and consequently advance success rates of CRM activities.

\section{References}

AHMAD, R.; BUTTLE, F. (2002). Customer retention management: a reflection of theory and practice. Marketing Intelligence \& Planning, 20(3): 149-161. http://dx.doi.org/10.1108/02634500210428003

ALT, R.; PUSCHMANN, T.; ÖSTERLE, H. (2005). Erfolgsfaktoren im Customer Relationship Management. Zeitschrift für Betriebswirtschaft, 75(2): 185-208.

BERGER, P.D.; NASR, N.I. (1998). Customer lifetime value: Marketing models and applications. Journal of Interactive Marketing, 12: 17-30. http://dx.doi.org/10.1002/(SICI)1520-6653(199824)12:1<17::AID-DIR3>3.0.CO;2-K

BERMEJ O, G.; RODRÍGUEZ MONROY, C. (2010). How to measure customer value and its relationship with shareholder value in a business-to-business market. Intangible Capital, 6(2): 142-161. http://dx.doi.org/10.3926/ic.2010.v6n2.p142-161 
BUGHIN, J.; DOOGAN, J.; VETVIK, O. (2010). A new way to measure word-ofmouth marketing. McKinsey Quarterly, April.

DAWKINS, P.M.; REICHHELD, F.F. (1990). Customer retention as a competitive weapon. Directors and Board, 14: 42-47.

FRANKE, N.; SCHREIER, M.; KAISER, U. (2010). The "I designed it myself" effect in mass customization. Management Science, 56(1): 125-140. http://dx.doi.org/10.1287/mnsc.1090.1077

GUPTA, S.; ZEITHAML, V. (2006). Customer Metrics and Their Impact on Financial Performance. Marketing Science, 25(6): 718-739. http://dx. doi.org/10.1287/mksc.1060.0221

HOGAN, J.; LEMON, K., LIBAI, B. (2003). What is the True Value of a Lost Customer? Journal of Service Research, 5(3): 196-208. http://dx.doi.org/10.1177/1094670502238915

HOGAN, J.; LEMON, K.; LIBAI, B. (2004). Quantifying the Ripple: Word-Of-Mouth and Advertising Effectiveness, Journal of Advertising Research, 44(3): 271-280. http://dx.doi.org/10.1017/S0021849904040243

ITTNER, C.; LARCKER, D.F. (1996). Measuring the impact of quality initiatives on firm financial performance. Soumeh Ghosh, Donald Fedor, eds. Advances in the Management of Organizational Quality, JAI Press, Greenwich, CT, 1: 1-37.

IYENGAR, R.; ANSARI, A.; GUPTA, S. (2007). A Model of Customer Learning for Service Quality and Usage. Journal of Marketing Research, 44: 529-544. http://dx.doi.org/10.1509/imkr.44.4.529

JAIN, D.; SINGH, S.S. (2002). Customer Lifetime Value research in Marketing: A review and future directions. Journal of Interactive Marketing, 16(2): 34-36. http://dx.doi.org/10.1002/dir.10032

KIM, J.; SUH, E.; HWANG, H. (2003). A Model for evaluating the effectiveness of CRM using the balanced scorecard. Journal of Interactive Marketing, 17(2): 5-19. http://dx.doi.org/10.1002/dir.10051

KUMAR, V.; PETERSEN, J.; LEONE, R. (2007). How valuable is Word of Mouth? Harvard Business Review, October: 139-146. 
KUMAR, V.; RAJAN, B. (2009). Profitable Customer Management: Measuring and Maximizing Customer Lifetime Value. Management Accounting Quarterly, 10(3): $1-18$.

KUMAR, V.; AKSOY, L.; DONKERS, B.; VENKATESAN, R.; WIESEL, T.; TILLMANNS, S. (2010). Undervalued or Overvalued Customers: Capturing Total Customer Engagement Value. Journal of Service Research, 13(3): 297-310. http://dx.doi.org/10.1177/1094670510375602

LEE, J.; LEE, J.; FEICK, L. (2006). Incorporating word-of-mouth effects in estimating customer lifetime value. Journal of Database Marketing \& Customer Strategy Management, 14(1): 29-39. http://dx.doi.org/10.1057/palgrave.dbm.3250033

MAGRO, D.; GOY, A. (2008). Towards a first Ontology for Customer Relationship Management. Proceedings of the 5th International Conference on Soft Computing as Transdisciplinary Science and Technology: 637-643. http://dx.doi.org/10.1145/1456223.1456352

PAYNE, A.; FROW, P. (2005). A Strategic Framework for Customer Relationship Management. Journal of Marketing, 69: 167-176. http://dx.doi.org/10.1509/jmkg.2005.69.4.167

Peterson, J. A.; McAlister, L.; Reibstein, D.J.; Winer, R.S.; Kumar, V.; Atkinson, G. (2009). Choosing the Right Metrics to Maximize Profitability and Shareholder Value. Journal of Retailing, 85(1): 95-111. http://dx.doi.org/10.1016/i.jretai.2008.11.004

PILLER, F. (2006). User Innovation: Der Kunde als Initiator und Beteiligter im Innovationsprozess. in: DROSSOU, O. and KREMPL, S. (Authors): Open Innovation. Freier Austausch von Wissen als soziales, politisches und wirtschaftliches Erfolgsmodell. Hannover: Heise-dpunkt.

PINTO, H.S.; MARTINS, J.P. (2004). Ontologies: How can they be built? Knowledge and Information Systems, 6: 441-464. http://dx.doi.org/10.1007/s10115-003-0138-1

REICHHELD, F.F. (1996). Learning from Customer Defection. Harvard Business Review, March-April: 56-69.

REINARTZ, W.J.; KRAFFT, M.; HOYER, W.D. (2004). The customer relationship management process: Its measurement and impact on performance. Journal of Marketing Research, 41: 293-305. http://dx.doi.org/10.1509/jmkr.41.3.293.35991 
RICHARDS, K.A.; JONES, E. (2008). Customer relationship management: finding value drivers. Industrial Marketing Management, 37(2): 120-130. http://dx. doi.org/10.1016/j.indmarman.2006.08.005

RYALS, L. (2002). Are your customers worth more than money? Journal of Retailing and Consumer Services, 9(5): 241-251. http://dx.doi.org/10.1016/S0969-6989(02)00005-X

RYALS, L. (2008). Determining the indirect value of a customer. Journal of Marketing Management Special Issue Marketing/ Finance Interface, 24(7-8): 847864. http://dx.doi.org/10.1362/026725708X345542

SEGGIE, S.H.; CAVUSGIL E.; PHELAN S.E. (2007). Measurement of return on marketing investment: A conceptual framework and the future of marketing metrics. Industrial Marketing Management, 36(6): 834-841. http://dx. doi.org/10.1016/i.indmarman.2006.11.001

STAHL, H.K.; MATZLER, K.; HINTERHUBER, H.H. (2003). Linking customer lifetime value with shareholder value. Industrial Marketing Management, 32(4): 267-279. http://dx.doi.org/10.1016/S0019-8501(02)00188-8

TEO, T.S.H.: DEVADOSS, P.; PAN, S.L. (2006). Towards a holistic perspective of customer relationship management (CRM) implementation: A case study of the Housing and Development Board, Singapore. Decision Support System, 42: 16131627. http://dx.doi.org/10.1016/i.dss.2006.01.007

URBAN, G. (2005). Customer Advocacy: A New Era in Marketing? Journal of Public Policy \& Marketing, 24(1), 155-159. http://dx.doi.org/10.1509/ippm.24.1.155.63887

VON HIPPEL, E.; KATZ, R. (2002). Shifting innovation to users via toolkits. Management Science, 48(7): 821-833. http://dx.doi.org/10.1287/mnsc.48.7.821.2817

ZABLAH, A.R.; BELLENGER, D.N.; JOHNSTON, W.J. (2004). An evaluation of divergent perspectives on customer relationship management: Towards a common understanding of an emerging phenomenon. Industrial Marketing Management, 33: 475-489. http://dx.doi.org/10.1016/j.indmarman.2004.01.006

ZHANG, J.; ASHUTOSH, D.; FRIEDMANN, R. (2010). Customer Loyalty and Lifetime Value: An Empirical Investigation of Consumer Packed Goods. Journal of Marketing Theory and Practice, 18(2): 127-139. http://dx.doi.org/10.2753/MTP10696679180202 
Intangible Capital, 2011 (www.intangiblecapital.org)

\section{(c)}

Article's contents are provided on a Attribution-Non Commercial 3.0 Creative commons license. Readers are allowed to copy, distribute and communicate article's contents, provided the author's and Intangible Capital journal's names are included. It must not be used for commercial purposes. To see the complete licence contents, please visit http://creativecommons.org/licenses/by-nc/3.0/es/ 